\title{
Determination of urinary trypsin inhibitor provides insight into postoperative complications in patients following esophagectomy
}

\author{
ICHIRO AKAGI, MASAO MIYASHITA, KEN TAKAHASHI, TAKESHI MATSUTANI, AKIHISA MATSUDA, \\ TSUTOMU NOMURA, HIROSHI MAKINO, NOBUTOSHI HAGIWARA and EIJI UCHIDA
}

Division of Surgery for Organ Function and Biological Regulation, Nippon Medical School, Tokyo, Japan

Received July 4, 2011; Accepted December 5, 2011

DOI: $10.3892 /$ etm.2012.554

\begin{abstract}
The urinary trypsin inhibitor (UTI) is responsible for most of the antitryptic activity in urine and is excreted in increased amounts in urine under certain pathological conditions such as cancer and bacterial infections. Our aim in this study was to better understand the mechanisms responsible for the increase in UTI excretion on surgical stress and thus to better appreciate the information provided by inflammatory mediators. Thirty-one consecutive patients who underwent radical esophagectomy for esophageal cancer were investigated in this study. We determined serum UTI and polymorphonuclear cell elastase (PMNE), urine UTI and evaluated the effectiveness of preoperative administration of methylprednisolone on the postoperative clinical course and adverse inflammatory reactions. The results revealed that urine UTI and serum PMNE levels in the steroid group were significantly lower than those in the non-steroid group. In addition, UTI levels correlated positively with serum levels of aminotransferases. More importantly, the maximum level of urine UTI in patients without complications was lower than that in patients with complications. These results suggest that urine UTI provides useful information concerning postoperative clinical course, and that preoperative administration of methylprednisolone may contribute to decrease postoperative complications following esophagectomy.
\end{abstract}

\section{Introduction}

Major surgery is associated with a transient severe inflammatory response involving the release of proinflammatory mediators and leads to systemic inflammation (1). Esophagectomy for esophageal carcinoma is one of the most invasive surgical procedures and is associated with a generalized systemic inflammatory response characterized by the activation of proinflammatory cytokines and other chemical mediators (2).

Correspondence to: Dr Ichiro Akagi, Division of Surgery for Organ Function and Biological Regulation, Nippon Medical School, 1-1-5 Sendagi, Tokyo 113-8602, Japan

E-mail: ichiro@nms.ac.jp

Key words: urinary trypsin inhibitor, steroid, esophageal cancer
After inflammatory stimulus, the pattern of plasma proteins synthesized by the liver changes significantly. In general, the concentration of positive acute phase proteins (APPs), including $\mathrm{C}$-reactive protein (CRP), increases. These proteins are widely used as indicators in rapid diagnosis and the assessment of the response to therapy in inflammatory diseases. In addition, it has been reported that polymorphonuclear cell elastase (PMNE) is released from granulocytes during surgery and that the postoperative serum level of PMNE is a good indicator of surgical stress. More importantly, the monitoring of PMNE was found to be more useful than that of serum CRP for estimation of the inflammatory status and early detection of an acute-phase response (3-5).

The urinary trypsin inhibitor (UTI) is one of the Kunitztype trypsin inhibitors found in human urine and is synthesized by the inter- $\alpha$-trypsin inhibitor (ITI) family (6). As previously reviewed by Fries and Blom (7), UTI is responsible for most of the antitryptic activity in urine and is excreted in increased amounts in urine under certain pathological conditions such as cancer and bacterial infections (8-10). Thus, UTI is an important anti-inflammatory substance, and is also considered to be a positive APP $(11,12)$. UTI has previously been suggested as a possible screening test for bacterial and/or viral infections (13). More importantly, the urine concentration of UTI could be useful for predicting the risk of complications and outcome of bone marrow transplantation (14).

We previously reported that preoperative administration of methylprednisolone successfully suppresses the release of certain indicators of response to surgical injury such as IL-6 and IL-8, and plays a significant role in the prevention of systemic inflammatory responses (15). Postoperative complications, so-called stress-induced organ dysfunction states, are thought to be caused by an uncontrolled inflammatory response due to the overproduction of proinflammatory cytokines and chemokines $(3,16)$. However, the mechanisms involved in reduced postoperative complications upon preoperative administration of methylprednisolone have not been clearly elucidated (17-19). Focusing on UTI and PMNE, our aim in the present study was to better understand the relationship between steroid and inflammatory mediators and thus to better appreciate the information provided by preoperative administration of methylprednisolone. We determined serum UTI and PMNE and urine UTI levels using an enzyme-linked immunosorbent assay (ELISA). We also evaluated the preoperative adminis- 
Table I. Comparison of the clinical features between the steroid and the non-steroid group.

\begin{tabular}{lccc}
\hline Features & Steroid group $(\mathrm{n}=19)$ & Non-steroid group $(\mathrm{n}=12)$ & P-value \\
\hline Male/female & $17 / 2$ & $8 / 4$ & 0.12 \\
Age (year), mean \pm SD & $60.9 \pm 10.2$ & $63.7 \pm 9.2$ & 0.46 \\
Operative time (min) & $498.6 \pm 49.9$ & $421.8 \pm 80.0$ & 0.08 \\
Intraoperative blood loss (ml) & $844.3 \pm 364.7$ & $891.9 \pm 369.0$ & 0.56 \\
Tumor stage (I:II:III:IV) & $4: 3: 5: 7$ & $5: 3: 1: 3$ & 0.40 \\
\hline
\end{tabular}

tration of methylprednisolone on the postoperative clinical course and adverse inflammatory reactions.

\section{Patients and methods}

Patients and study design. Thirty-one consecutive patients who underwent radical esophagectomy for esophageal cancer at Nippon Medical School Main Hospital between 2002 and 2004 were investigated in this study. The patients did not receive previous intravenous treatment with UTI. Patients who had a preoperative inflammatory reaction within 7 days prior to surgery, preoperative complications such as liver cirrhosis or diabetes mellitus, or tuberculosis lesions were excluded from the study. There were no significant differences in preoperative characteristics between the patients in the steroid and the non-steroid groups (Table I). Therefore, even though the study was not performed in a randomized manner, it is reasonable to state that the data shown here suggest objective results. In the steroid group, $10 \mathrm{mg} / \mathrm{kg}$ body weight of methylprednisolone was administered intravenously to each patient just before the start of esophagectomy. Informed consent according to the Declaration of Helsinki was obtained from all patients.

Enzyme immunoassay for PMNE and UTI. Serum and urine samples were obtained and stored at $-80^{\circ} \mathrm{C}$ until being assayed. Serum PMNE was measured the day prior to surgery and $24 \mathrm{~h}$, $3,5,7$ and 14 days after the start of surgery by enzyme immunoassay (ELISA) using a commercial kit reagent (PMN Elastase; E. Merck, Germany). Plasma and urine UTI were measured using a one-step sandwich enzyme-linked immunosorbent assay (ELISA; Mochida Pharmaceutical Co., Tokyo, Japan). Briefly, purified anti-ulinastatin immunoglobulins (Igs) were labeled with horseradish peroxidase (Toyobo Enzymes, Tokyo, Japan). Each well in the ELISA plates was coated with $100 \mu 1$ of anti-ulinastatin Igs $(5 \mathrm{mg} / \mathrm{ml})$ in carbonate buffer $(\mathrm{pH} \mathrm{9.5)}$ at $25^{\circ} \mathrm{C}$ for $12 \mathrm{~h}$. Coated plates were washed and subsequently blocked with $0.5 \%$ bovine serum albumin (BSA) in phosphatebuffered saline (PBS) ( $\mathrm{pH} \mathrm{6.4)} \mathrm{for} 1 \mathrm{~h}$ at room temperature. Then $20 \mu \mathrm{l}$ of the diluted samples or standards was added, after which $80 \mathrm{ml}$ of peroxidase-conjugated anti-ulinastatin Igs in $10 \%$ (v/v) rabbit serum/PBS ( $\mathrm{pH}$ 6.4) was added. The plate was incubated for $30 \mathrm{~min}$ at $37^{\circ} \mathrm{C}$ and washed three times with $400 \mu \mathrm{l}$ of physiological saline containing $0.05 \%$ Tween-20 (Biosciences Inc., La Jolla, CA, USA). Then $100 \mu \mathrm{l}$ of freshly prepared tetramethylbenzydine containing hydrogen peroxide $(0.02 \%)$ was added and incubated for $10 \mathrm{~min}$ at room tempera- ture. The reaction was terminated by the addition of $100 \mu 1$ of $0.5 \mathrm{~mol} \mathrm{H}_{2} \mathrm{SO}_{4}$. The absorbance was read at $450 \mathrm{~nm}$ using a microplate reader (ImmunoMini NJ-2300; Sic, Tokyo, Japan). All samples were assayed in duplicate.

Definition of postoperative complications. The postoperative course of each patient was monitored daily, and the complications were defined as follows. Pulmonary complications were defined by the presence of massive atelectasis, pulmonary edema, or pneumonia. Postoperative hyperbilirubinemia was defined as the peak total bilirubin level $>4 \mathrm{mg} / \mathrm{dl}$. Anastomotic leakage was diagnosed by gastrography and clinical features. Liver dysfunction was defined as either the aspartate aminotransferase (AST) or alanine aminotransferase (ALT) value $>200 \mathrm{IU} / 1$.

Statistical analysis. The Mann-Whitney's U test, Chi-square test, and repeated measure ANOVA were used to determine significant differences between the two groups. P-values of $<0.05$ were considered significant.

\section{Results}

Effect of steroid therapy on the changes in acute phase parameters. Postoperative changes in the levels of serum UTI, serum PMNE and urine UTI were compared between both groups. Compared with the non-steroid group, the steroid group had significantly lower levels of urine UTI and serum PMNE (Fig. 1A and C). Regarding the level of serum UTI, no significant difference was noted between the groups (Fig. 1B).

Correlation between urine UTI and serum levels of aminotransferases. For the evaluation of hepatic injury, the peak levels of AST and ALT in the serum were correlated with that of urine UTI. The peak levels of UTI correlated positively with those of aminotransferases (Fig. 2).

Correlation between urine UTI and postoperative complications. The postoperative complications are shown in Fig. 3. The maximum level of urine UTI in patients without complications was lower than that in patients with complications (Fig. 4).

\section{Discussion}

This study was designed to understand the relationship between steroid and inflammatory mediators and to evaluate 

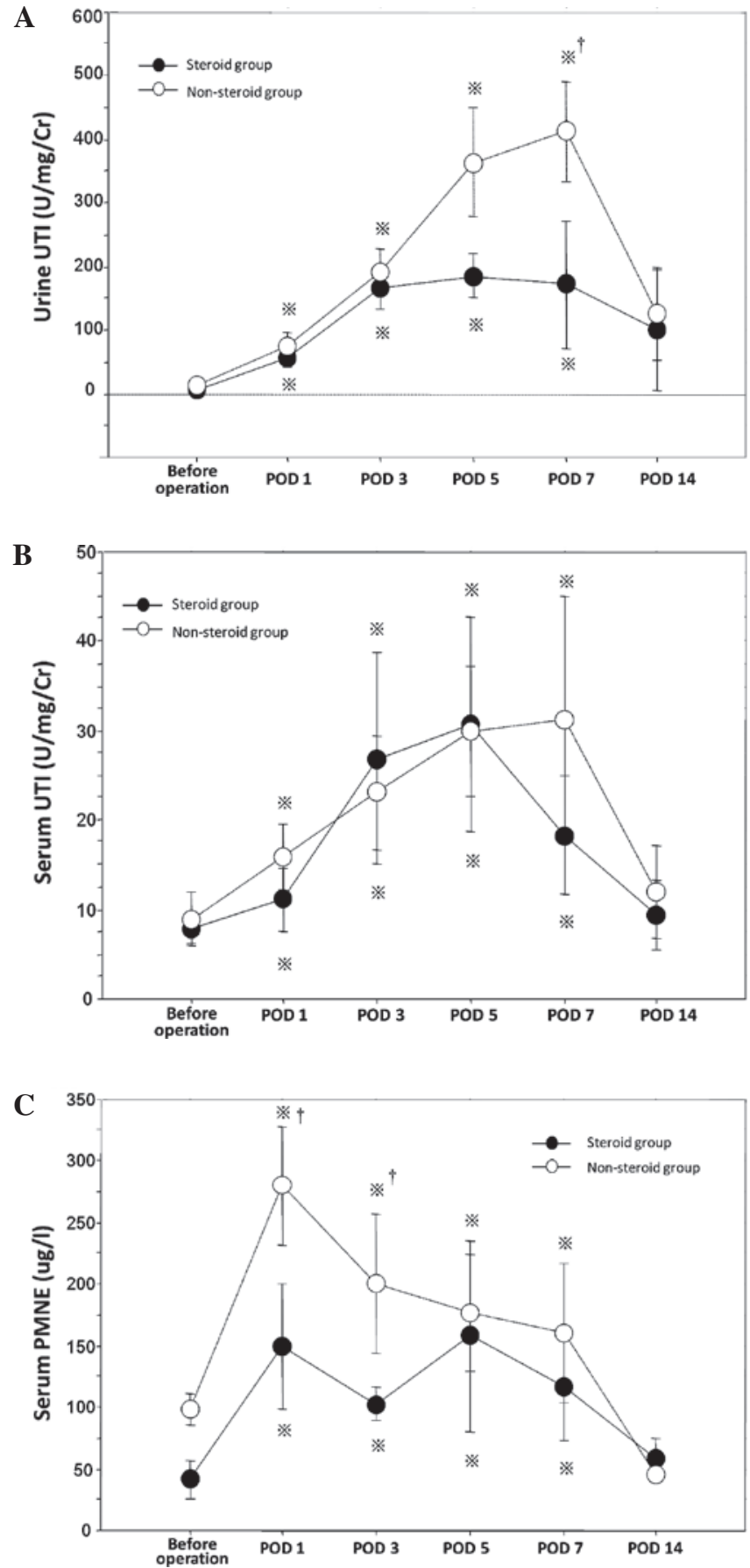

Figure 1. Changes over postoperative time in (A) urine UTI, (B) serum UTI and (C) PMNE levels in the steroid $(\mathrm{n}=19)$ (filled circles) and the non-steroid $(n=12)$ (open circles) groups. Data are expressed as the mean \pm SE. ${ }^{*} \mathrm{P}<0.05$ vs. the preoperative values in the same group; ${ }^{\dagger} \mathrm{P}<0.05$ vs. the non-steroid group at the same point. POD, postoperative day.

the effects of preoperative administration of methylprednisolone. Patients with esophageal cancer scheduled for surgery were selected for the following reasons. While a balance of proinflammatory and anti-inflammatory mediators is essential for the appropriate immune response of patients, the postoperative overproduction of proinflammatory mediators may lead to tissue damage via the production of free oxygen species and may also result in systemic inflammatory response syndrome (SIRS) with subsequent multiorgan failure (20). Surgical treatment of esophageal cancer is one of the most stressful surgical
A

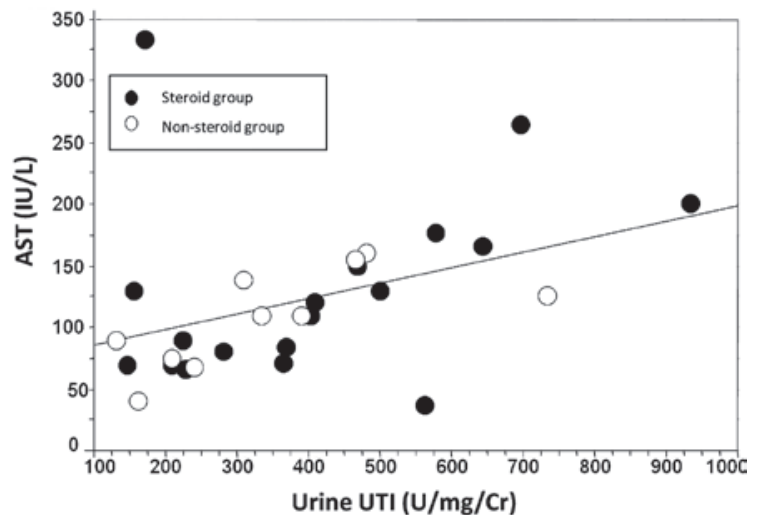

B

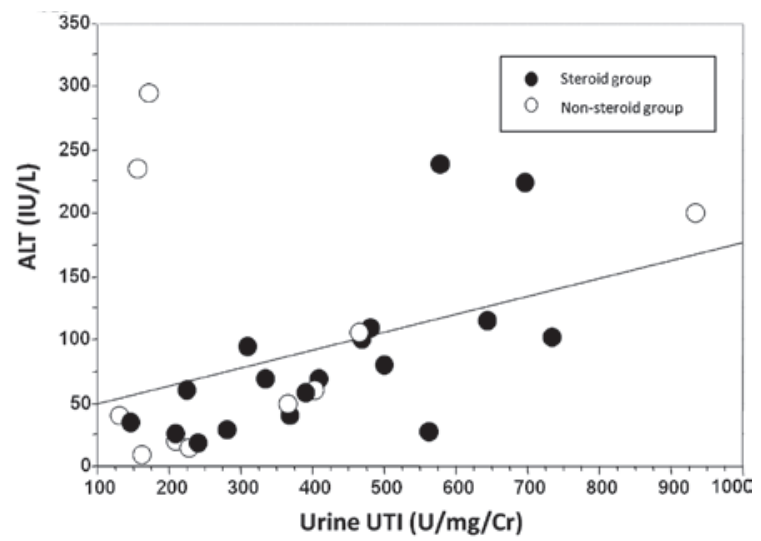

Figure 2: (A) Correlation between the peak levels of urine UTI and aspartate aminotransferase (AST) in all of the studied patients $(n=31 ; r=0.64$, $\mathrm{P}=0.001)$. (B) Correlation between the peak levels of urine UTI and alanine aminotransferase (ALT) in all of the studied patients $(n=31)(r=0.48, P=0.02)$.

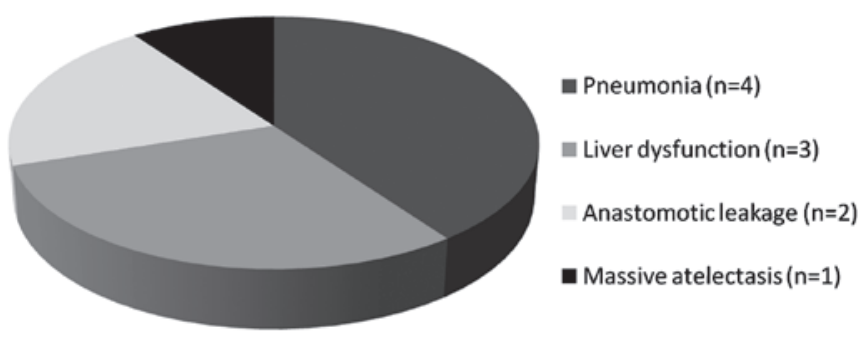

Figure 3. The distribution of postoperative complications.

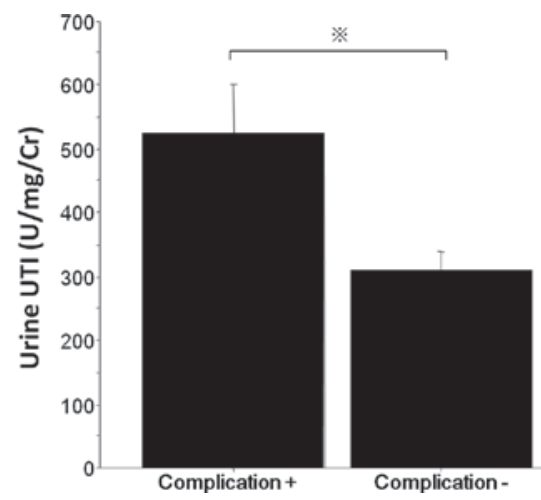

Figure 4. Peak levels of urine UTI in patients with complications $(+)(\mathrm{n}=10)$ and without complications (-) $(\mathrm{n}=21)$. The peak level of urine UTI in patients without complication was lower than that in patients with complication. ${ }^{*} \mathrm{P}<0.05$ in the Student's t-test. 
procedures, and the frequency of postoperative organ failure remains high (21-23). Esophageal cancer surgery was therefore selected as one of the most appropriate procedures for evaluating the effects of steroids on surgical stress.

UTI is one of the protease inhibitors, and is produced in the liver and kidneys $(24,25)$. It is also one of the acute phase reactants $(11,13)$. The amount of this inhibitor excreted in the urine is considered proportional to the invasiveness of an insult to the host, typically major surgery (14). In the present study, the concentration of serum UTI was significantly lower than that of urine UTI, and no significant difference was noted between the steroid and non-steroid group (Fig. 1). These results are in accord with those from other studies which found that the concentration of serum UTI of patients undergoing partial hepatectomy was only slightly increased and even appeared to be unmodified during the acute phase response (12). Indeed, owing to its small amount, UTI circulating in the blood secondarily diffuses into extracellular spaces and reaches tissues. On the other hand, most of it is quickly excreted in the urine (26). Therefore, the amount of UTI present in urine appears to be a better indicator of UTI released in circulating plasma.

Methylprednisolone has been known to suppress the release of mediators (autocrine and paracrine), such as IL-6, IL-8 and PMNE, following surgical injury, and was found to play a significant role in the prevention of developing the subsequent spread of inflammation. PMNE metabolizes inter$\alpha$-inhibitor ( $\mathrm{I} \alpha \mathrm{I})$ to UTI, which then suppresses the activity of PMNE, thus forming a homeostatic negative feedback loop (27). It has been suggested that when the balance is upset and PMNE activity exceeds that of UTI, inflammation develops (28). As mentioned by Faarvang and Lauritsen (29), increased excretion of urine UTI has been recognized in response to inflammatory conditions. This was confirmed by our results which demonstrated that levels of urine UTI and serum PMNE in the steroid group were significantly decreased compared to those in the non-steroid group (Fig. 1).

During the acute-phase response, a large number of mediators which can cause postoperative complications are generated, and all of these may be markers of inflammation. It has been reported that there is a strong correlation between the concentrations of CRP in whole blood and urine UTI $(10,30)$. More importantly, UTI is a better predictor of the subsequent spread of inflammation compared to CRP (31). In all of our patients, urine UTI levels correlated positively with serum levels of aminotransferases (Fig. 2). This result supports the hypothesis that UTI reflects liver injury as well.

It is of great importance that the possible clinical effects of preoperative steroid administration include the prevention of postoperative complications. Yamashita et al (32) and Shirabe (33) previously reported that the administration of steroids in liver surgery results in decreased values of immunosuppressive acid protein and postoperative positive rate of serum Candida antigen, which is a marker of bacterial translocation. Similar findings were reported for other surgical operations. Shimada et al (34) reported that morbidity rates including hyperbilirubinemia, anastomotic leakage, and liver dysfunction in patients with esophagectomy were significantly lower in a steroid group than in a non-steroid group. In addition, the median hospital stay was reported to be shorter in a steroid group, and adverse effects of steroid use, such as abnormality in glucose tolerance and delay in wound healing, did not occur following liver surgery (35). In the present study, the level of urine UTI in the steroid group was decreased compared to that in the non-steroid group (Fig. 1), and the maximum level of urine UTI in patients without complications was significantly lower than that in patients with complications (Fig. 4). According to these results, the UTI concentration predicts complications following esophagectomy, and the suppression of UTI levels induced by steroid administration may be one of the reasons for the reduction in postoperative complications.

A study with a much larger population is required before any firm conclusions can be drawn. Based on findings of the present study, it was suggested that urine UTI provides useful information on postoperative clinical course, and that preoperative administration of methylprednisolone may contribute to decrease postoperative complications following esophagectomy.

\section{Acknowledgements}

We thank the hospital committees for endorsing this study.

\section{References}

1. Cruickshank AM, Fraser WD, Burns HJ, Van Damme J and Shenkin A: Response of serum interleukin-6 in patients undergoing elective surgery of varying severity. Clin Sci (Lond) 79: 161-165, 1990.

2. Ono S, Aosasa S and Mochizuki H: Effects of a protease inhibitor on reduction of surgical stress in esophagectomy. Am J Surg 177: 78-82, 1999.

3. Sakamoto K, Arakawa H, Mita S, et al: Elevation of circulating interleukin 6 after surgery: factors influencing the serum level. Cytokine 6: 181-186, 1994.

4. Kato M, Suzuki H, Murakami M, Akama M, Matsukawa S and Hashimoto Y: Elevated plasma levels of interleukin-6, interleukin-8, and granulocyte colony-stimulating factor during and after major abdominal surgery. J Clin Anesth 9: 293-298, 1997.

5. Sato N, Murakami K, Ishida K, Ikeda K and Saito K: Pulmonary hypertension and polymorphonuclear leukocyte elastase after esophageal cancer operations. Ann Thorac Surg: 51: 754-758, 1991.

6. Salier JP, Rouet P, Raguenez G and Daveau M: The inter-alphainhibitor family: from structure to regulation. Biochem J 315: $1-9,1996$.

7. Fries E and Blom AM: Bikunin - not just a plasma proteinase inhibitor. Int J Biochem Cell Biol: 32: 125-137, 2000.

8. Mizon C, Balduyck M, Bonneterre JP and Mizon J: Urinary trypsin inhibitory capacity determination: study in patients with disseminated cancers. Bull Cancer 70: 266-270, 1983.

9. Chawla RK, Rausch DJ, Miller FW, Vogler WR and Lawson DH: Abnormal profile of serum proteinase inhibitors in cancer patients. Cancer Res 44: 2718-2723, 1984.

10. Gosset D, Mizon C, Savinel P, et al: Clinical value of the determination of urinary antitrypsin activity. Presse Med 17: 329-332, 1988 (In French).

11. Kuwajima S, Matsui T, Kitahashi S, et al: Automated measurement of trypsin inhibitor in urine with a centrifugal analyzer: comparison with other acute phase reactants. Clin Biochem 23: 167-171, 1990 .

12. Noie T, Sugawara Y, Harihara Y, et al: Kinetics of urinary trypsin inhibitor in patients undergoing partial hepatectomy. Scand J Gastroenterol 36: 410-416, 2001.

13. Piette AM, Saba J, Bernard N, et al: Urinary trypsin inhibitory activity for the diagnosis of bacterial infection: a prospective study in 690 patients. Eur J Med 1: 273-276, 1992.

14. Yamada S, Takatsuka H, Takemoto Y, et al: Urinary trypsin inhibitor concentration can predict the immunological insult of chemotherapy and complications after bone marrow transplantation. Bone Marrow Transplant 27: 195-199, 2001.

15. Takeda S, Takeda S, Kim C, et al: Preoperative administration of methylprednisolone attenuates cytokine-induced respiratory failure after esophageal resection. J Nippon Med Sch 70: 16-20, 2003. 
16. Sato N, Koeda K, Ikeda K, et al: Randomized study of the benefits of preoperative corticosteroid administration on the postoperative morbidity and cytokine response in patients undergoing surgery for esophageal cancer. Ann Surg 236: 184-190, 2002.

17. Bone RC, Fisher CJ Jr, Clemmer TP, Slotman GJ, Metz CA and Balk RA: A controlled clinical trial of high-dose methylprednisolone in the treatment of severe sepsis and septic shock. N Engl J Med 317: 653-658, 1987.

18. Tonnesen E, Wanscher M, Hohndorf K, et al: Effect of methylprednisolone on the cytokine response in patients undergoing lung surgery. Acta Anaesthesiol Scand 37: 410-414, 1993.

19. Miyashita M: Controversy of corticosteroids in septic shock. J Nippon Med Sch 77: 67-70, 2010.

20. American College of Chest Physicians/Society of Critical Care Medicine Consensus Conference: Definitions for sepsis and organ failure and guidelines for the use of innovative therapies in sepsis. Crit Care Med 20: 864-874, 1992.

21. Swisher SG, Hunt KK, Holmes EC, Zinner MJ and McFadden DW: Changes in the surgical management of esophageal cancer from 1970 to 1993 . Am J Surg 169: 609-614, 1995.

22. Isono K, Sato H and Nakayama K: Results of a nationwide study on the three-field lymph node dissection of esophageal cancer. Oncology 48: 411-420, 1991.

23. Fok M, Law SY and Wong J: Operable esophageal carcinoma: current results from Hong Kong. World J Surg 18: 355-360, 1994

24. Kaumeyer JF, Polazzi JO and Kotick MP: The mRNA for a proteinase inhibitor related to the HI-30 domain of inter-alphatrypsin inhibitor also encodes alpha-1-microglobulin (protein HC). Nucleic Acids Res 14: 7839-7850, 1986.

25. Sugiki M, Sumi H, Maruyama M, Yoshida E and Mihara H: Clearance and distribution of acid-stable trypsin inhibitor (ASTI). Enzyme 42: 31-38, 1989.
26. Mizon C, Piva F, Queyrel V, Balduyck M, Hachulla E and Mizon J: Urinary bikunin determination provides insight into proteinase/ proteinase inhibitor imbalance in patients with inflammatory diseases. Clin Chem Lab Med 40: 579-586, 2002.

27. Kobayashi H: Endogenous anti-inflammatory substances, inter-alpha-inhibitor and bikunin. Biol Chem 387: 1545-1549, 2006.

28. Ogawa M, Nishibe S, Mori T and Neumann S: Effect of human urinary trypsin inhibitor on granulocyte elastase activity. Res Commun Chem Pathol Pharmacol 55: 271-274, 1987.

29. Faarvang HJ and Lauritsen OS: Circadian variations in sensitivity to glucocorticoid evaluated by urinary trypsin inhibitor excretion. Proc Soc Exp Biol Med 120: 338-340, 1965.

30. Ueki M, Yokono S, Taie S, Nogaya J, Komatsu H and Ogli K: Changes of urinary ulinastatin and serum CRP after elective surgery for gastric cancer. Masui 45: 933-936, 1996 (In Japanese).

31. Pugia MJ and Lott JA: Pathophysiology and diagnostic value of urinary trypsin inhibitors. Clin Chem Lab Med 43: 1-16, 2005.

32. Yamashita Y, Shimada M, Hamatsu T, et al: Effects of preoperative steroid administration on surgical stress in hepatic resection: prospective randomized trial. Arch Surg 136: 328-333, 2001.

33. Shirabe K, Takenaka K, Yamatomto K, et al: Impaired systemic immunity and frequent infection in patients with Candida antigen after hepatectomy. Hepatogastroenterology 44: 199-204, 1997.

34. Shimada H, Ochiai T, Okazumi S, et al: Clinical benefits of steroid therapy on surgical stress in patients with esophageal cancer. Surgery 128: 791-798, 2000.

35. Aldrighetti L, Pulitano C, Arru M, et al: Impact of preoperative steroid administration on ischemia-reperfusion injury and systemic responses in liver surgery: a prospective randomized study. Liver Transpl 12: 941-949, 2006. 